Revista de

Contabilidade e

Organizações

www.rco.usp.br
DOI: http://dx.doi.org/10.11606/issn.1982-6486.rco.2018.151837

Journal of

Accounting and

Organizations

\title{
Escolha de carreira: o Dark Triad revela revela interesses de estudantes de Contabilidade
}

\author{
Career choice: the dark triad reveals interests of accounting students \\ Márcia Figueredo D'Souza ${ }^{\mathrm{a}}$; Gerlando Augusto Sampaio Franco de Lima ${ }^{\mathrm{b}}$ \\ ${ }^{a}$ Universidade do Estado da Bahia \\ ${ }^{b}$ Universidade de Illinois
}

\section{Palavras-chave}

Carreira em Contabilidade.

Traços de personalidade.

Dark Triad.

Educação Contábil.

\section{Resumo}

Três traços de personalidades socialmente sombrios, mas não patológicos, compõem o chamado Dark Triad: Narcisismo, o Maquiavelismo e a Psicopatia. Analisamos a influência do Dark Triad sobre os interesses da carreira profissional pretendida por estudantes de graduação em Ciências Contábeis. Foi aplicado questionário em cursos de graduação em contabilidade de universidades brasileiras públicas e privadas. Os mais de 1400 estudantes que participaram têm preferência pela carreira de Auditoria e Contabilidade em organizações privadas. A satisfação profissional, seguida da remuneração são os interesses que mais impulsionam os estudantes na escolha de carreira. O Dark Triad para estes estudantes impulsiona interesses e objetivos associados a manipulação, superioridade, exibicionismo e poder.

\begin{abstract}
Three socially dark personality traits, all non-pathological, compose the Dark Triad: Narcissism, Machiavellianism and Psychopathy. We analyzed the influence of the Dark Triad on the professional career interests of students enrolled in accounting undergraduate courses. A questionnaire was applied to undergraduate courses from public and private Brazilian universities. More than 1,400 students participated and expressed their preferences towards the Auditing and Accounting in private organizations careers. Professional satisfaction, followed by remuneration, are the interests that mostly encouraged students to make their career choice. The personality traits that compose the Dark Triad for these students stimulate interests and objectives associated with manipulation, superiority, exhibitionism and power.
\end{abstract}

\section{Implicações práticas}

Recrutadores para carreiras correlatas a Auditoria e Contabilidade podem usar os resultados na seleção de candidatos. Traços de personalidade como os analisados podem ser observados para a composição de equipes, promoções e na alocação de projetos e missões específicas. Ainda, tais traços podem ser verificados por docentes na área, tanto na dinâmica com as turmas. Reguladores podem considerar tais aspectos no desenho de políticas de combate à atitudes profissionais desonestas, como difusão de programas de ética e compliance.

Copyright (C) 2018 FEA-RP/USP. Todos os direitos reservados

\section{INTRODUÇÃO}

A escolha e interesse de carreira profissional são influenciados por fatores externos como mercado de trabalho e situação econômica, além de fatores internos e individuais como educação, históricos familiares e atitudes. Por vezes, essa escolha é limitada por fatores socioculturais e valores pessoais (Agarwala, 2008), mas também pode ser impulsionada pela obtenção de sucesso profissional (Judge, Cable, Boudreau, \& Bretz, 1995), representado por aspectos objetivos ou extrínsecos, tais como salário, posição hierárquica ou status, e aspectos subjetivos ou intrínsecos, tais como satisfação no trabalho (Spurk, Keller, \& Hirschi, 2016), influência familiar e de amigos mais próximos ou pela vocação (Auyeung \& Sands, 1997).

Autor Correspondente: Tel. (71) 3634-5310

E-mail: marciafdsouza@yahoo.com.br (M. F. D'Souza); gerlandolima@gmail.com (G. A. S. F. de Lima)

Universidade do Estado da Bahia. Rodovia BA-512 - até km 2,000 - Polo Petroquímico - Camaçari/BA - 42810440, Brasil. 
Entretanto, Lau e Shaffer (1999), Furnham, Hyde e Trickey (2014) argumentam que a personalidade, aspectos ambientais e culturais influenciam na vocação, na escolha, nos interesses e nos critérios de seleção de carreira para obtenção de sucesso profissional. Nessa direção, Sutin, Costa Jr., Miech e Eaton (2009) e Abele e Spurk (2009), relacionaram os traços de personalidade com os aspectos extrínsecos e intrínsecos de sucesso de carreira. Já Furnham, Hyde e Trickey (2014) preferiram relacionar traços sombrios de personalidade e medidas de valores e preferências que indicam as escolhas de carreira no ambiente de negócio.

Sobre traços sombrios de personalidade, Schneider, Matthew, McLarnon e Carswell (2017), com o objetivo de ampliarem o estudo sobre a relação entre a personalidade e os interesses da escolha de carreira, até então mais centrados nos traços do Big Five, examinaram o efeito do Dark Triad, composto dos traços de personalidade, não patológicos de Narcisismo, Maquiavelismo e Psicopatia (Jones \& Paulhus, 2014; Paulhus \& Williams, 2002). Com o mesmo propósito, outros pesquisadores se debruçaram a estudar essa relação em ambientes da área de negócios e contábil (Kowalski, Vernon, \& Schermer, 2017; Volmer, Koch, \& Göritz 2016; Spurk et al., 2016; Qin \& Xu, 2013; Jonason, Wee, \& Li, 2015; Jonason, Wee, Li, \& Jackson, 2014; Wakefield, 2008).

O Dark Triad é um cluster que reúne os constructos do Narcisismo, do Maquiavelismo e da Psicopatia, cujos traços possuem características sobrepostas, embora sejam construtos distintos e são caracterizados pelo caráter socialmente indesejável, com tendências para manipulação, ausência de afabilidade, autopromoção, frieza emocional, duplicidade e agressividade (Jones \& Paulhus, 2014; Paulhus \& Williams, 2002).

Quando se analisa as características dos traços individualmente, a autoridade, autossuficiência, superioridade, exibicionismo, exploração, vaidade e senso de direito são marcas do Narcisismo (Raskin \& Terry, 1988). Atitudes cínicas, ausência de princípios e manipulação para alcançar seus próprios interesses são referências do Maquiavelismo (Christie \& Geis, 1970), e a impulsividade e falta de culpa ou remorso em seus atos são atributos de indivíduos psicopatas (VanderBos, 2010).

Diante desse contexto, este estudo pretende responder à seguinte questão de pesquisa: qual a influência dos traços de personalidade do Dark Triad sobre os interesses de carreira profissional pretendida por estudantes de Ciências Contábeis? Para tanto, realizou-se uma pesquisa com 1.404 estudantes de contabilidade no contexto de 21 instituições de ensino privada e pública brasileiras, pela aplicação de um questionário autorrelato, na modalidade on-line e presencial. Foi possível constatar a influência dos traços do Dark Triad na escolha e interesse de carreira, sobretudo pelo interesse em ser superior, manipular, exibir-se, buscar o poder pelo alcance de posições de destaque nas empresas e pelo prestígio que a carreira profissional pode proporcionar.

Com base nos resultados, este estudo pretende contribuir teoricamente ampliando a discussão de investigações na área da educação contábil, uma vez que as investigações dessa natureza, concentram-se na análise dos fatores intrínsecos e extrínsecos de escolha de carreira (Omar, Zakaria, Ismail, LeySin, \& Selvakumar, 2015; Ahmed, K. Alam \& M. Alam, 1997; Law, 2010; Auyeung \& Sands, 2010), e aqueles que discutem personalidade, centraram-se nos traços do Big Five (Holt, Burke-Smalley, \& Jones, 2017) ou nos traços do Dark Triad, envolvendo os estilos vocacionais (Jonason et al., 2014) e interesses vocacionais (Kowalski et al., 2017). Este estudo preenche, portanto, uma lacuna teórica ao promover a interdisciplinaridade da área contábil e psicológica, cuja interlocução permite perceber uma predisposição à personalidade sombria nas atitudes dos estudantes de contabilidade, tema ainda pouco explorado na área.

Ainda, este estudo trata dos efeitos dos traços de personalidade nos estudantes e futuros profissionais, oferecendo parâmetros para recrutadores selecionarem candidatos à vaga de empregos na área contábil, sobretudo para empresas de auditoria que requerem profissionais com posturas imparciais e éticas. Por fim, tais traços podem ser observados por docentes na área, que sem a pretensão de mudar a personalidade dos estudantes, pode consideralas na dinâmica com as turmas, e mesmo reguladores podem considerar tais aspectos no desenho de políticas de combate à atitudes profissionais desonestas, como difusão de programas de ética e compliance.

\section{TRAÇOS DE PERSONALIDADE DO DARK TRIAD}

Paulhus e Williams (2002) investigaram os traços de personalidade não patológicos de Psicopatia, Narcisismo e Maquiavelismo, denominados Dark Triad. Os autores testaram as personalidades socialmente sombrias, em um grupo de 245 estudantes de graduação em psicologia. Para tanto, mapearam as três medidas relacionando-as com os fatores de personalidade do Big Five - extroversão, afabilidade, consciência, neuroticismo e abertura à experiência -, e com a classificação de autoavaliações de inteligência, talentos e habilidades cognitivas. 
Constataram que as medidas são moderadamente intercorrelacionadas, mas não são equivalentes. A baixa afabilidade se revelou como a única característica comum aos três grupos de traços. Os traços de Psicopatia se diferenciaram por assumirem baixo neuroticismo; os maquiavélicos e os psicopatas exibiram baixa pontuação em relação ao fator consciência; os narcisistas apontaram pequenas associações positivas com a capacidade cognitiva. O Narcisismo e a Psicopatia também foram associados com extroversão e abertura à experiência.

Cabe ressaltar que esses traços de personalidade são caracterizados como não patológicos, pois a intenção da pesquisa é a detecção de traços não clínicos, fundamentados na literatura da psicologia social, sem a pretensão de diagnosticar clinicamente os indivíduos. Jones e Paulhus (2011) diferenciam a patologia da não patologia argumentando que o nível clínico é um problema sério e requer ajuda profissional; já o subclínico é leve e permite que os indivíduos vivam normalmente em meio social.

Ao analisar os construtos que compõem os traços do Dark Triad, o Narcisismo foi investigado por Raskin e Terry (1988) que identificaram os fatores autoridade, autossuficiência, superioridade, exibicionismo, exploração, vaidade e senso de direito. Outras características são evidenciadas na literatura, tais como: ausência de afabilidade, autoaperfeiçoamento, autoestima elevada, extroversão, autopromoção, insensibilidade, busca de atenção e sensações, manipulação interpessoal, capacidade de influenciar e convencer, sensibilidade a críticas e desonestidade (Campbell, Goodie, \& Foster, 2004; Campbell, Bush, Brunell, \& Shelton, 2005; Campbell, W., Hoffman, Campbell, S., \& Marchisio, 2011; Chatterjee e Hambrick, 2007, 2011; Furtner, Rauthmann, \& Sachse, 2011; Hoffman, Strang, Kuhnert, Campbell, Kennedy, \& LoPilato, 2013; Jakobwitz \& Egan, 2006; Jones \& Paulhus, 2010, 2014; Maccoby, 2004; Paulhus \& Williams, 2002; Rosenthal \& Pittinsky, 2006; VandenBos, 2010).

A Psicopatia tem como marco atitudinal a impulsividade, a falta de culpa ou remorso em seus atos e o egocentrismo (Babiak \& Hare, 2006; Babiak, Neumann, \& Hare, 2010; Berg Lilienfeld, \& Waldman, 2013; Boddy, 2009, 2010, 2011; Jones \& Paulhus, 2010, 2014; Paulhus \& Williams, 2002; Smith \& Lilienfeld, 2013; VanderBos, 2010). Indivíduos psicopáticos conseguem realizar trabalhos duros, causam uma excelente primeira impressão, demonstram coragem e firmeza, possuem visão estratégica, tomam decisões arriscadas, convivem bem com decisões difíceis, são confiantes, objetivos, visionários, possuem uma boa rede de contatos e sobem hierarquicamente nas organizações pela confiança e lealdade que adquirem dos colegas de trabalho (Wexler, 2008).

O Maquiavelismo é um traço oriundo dos escritos de Maquiavel que se caracteriza por atitudes cínicas, ausência de princípios, manipulação dos outros de acordo com o seu ponto de vista e seus próprios interesses, cuja crença maior é a de que a manipulação interpessoal é a chave para o sucesso na vida (Christie \& Geis, 1970). Características como insensibilidade, ausência de afabilidade, baixos padrões de ética e moral, mentira/enganação, cálculo estratégico, oportunismo, capacidade de fazer aliados, orientação para o futuro - longo prazo, reputação, desonestidade, tática e estratégia são encontradas na literatura (Corzine, 1997; Hartmann \& Maas, 2010; Jones \& Figueredo, 2013; Jones \& Paulhus, 2009, 2010, 2011, 2014; Judge, Piccolo, \& Kosalka, 2009; Mchoskey, 1999; Paulhus \& Williams, 2002; VanderBos, 2010). Os traços de personalidade do Dark Triad têm sido objeto de vários estudos no contexto organizacional e acadêmico, entre eles, a escolha de carreira.

\section{CARREIRA E TRAÇOS DE PERSONALIDADE}

Na visão de Carpenter e Foster (1977) e Beynon, Toohey e Kishor (1998), a escolha de carreira é representada por um quadro tridimensional, composto por três fatores: (1) intrínseco (interesse no trabalho e trabalho pessoalmente satisfatório); (2) extrínseco (disponibilidade de emprego e ocupações bem remuneradas); e (3) interpessoais (influência dos pais ou pessoas mais próximos).

Outro fator que potencializa a escolha da carreira é a obtenção de sucesso profissional. Nesse particular, Judge et al. (1995) afirmam que sucesso na carreira é decorrente dos resultados psicológicos positivos ou realizações acumuladas como resultado de experiências ao longo do período de vida de trabalho, composta por duas categorias: carreira de sucesso extrínseco e intrínseco (Judge \& Bretz, 1994; Gattiker \& Larwood, 1988; Korman, WittigBerman, \& Lang, 1981). O componente extrínseco é o sucesso relativamente objetivo e observável como salário e número de promoções. Os resultados são altamente visíveis (Judge et al., 1995; Jaskolka, Beyer, \& Trice, 1985). O estudo de Spurk et al. (2016) considera como variáveis externas, o salário, a posição hierárquica ou status e o número de promoções.

Já a variável intrínseca e subjetiva é percebida pelo indivíduo por meio da sua autoavaliação sobre o progresso na carreira, tal como a satisfação no trabalho (Spurk et al., 2016; Abelle \& Spurk, 2009; Judge et al., 1995; Gattiker \& Larwood, 1988). Neste aspecto, Sutin et al. (2009) afirmam que a personalidade é um componente importante que pode moldar o ambiente de trabalho, sobretudo influenciar nas decisões sobre a carreira a ser seguida. 
Nesse sentido, estudiosos como Holland (1997), Jackson (1977) e Shermer e MacDougall (2011) desenvolveram escalas psicométricas para capturar essa tendência humana. Holland (1997) enunciou a teoria de personalidade vocacional RIASEC (Realista, Investigativa, Artística, Social, Empreendedora e Convencional). A escala Jackson Carrer Explorer (JCE) (Shermer \& MacDougall, 2011), versão modificada da Jackson Employment Interest Survey (JVIS, Jackson, 1977), também é outro instrumento bastante utilizado por pesquisas para captura de interesses vocacionais. As variações de instrumentos de captura dos interesses, estilos vocacionais e escolha de carreira que relacionam os aspectos objetivos e subjetivos, em especial traços de personalidade, enriquecem a literatura científica para estudos no âmbito educacional, profissional e organizacional.

Diversos autores têm se debruçado a estudar a relação e os efeitos dos traços de personalidade na escolha de carreira. Sutin et al. (2009), por exemplo, investigaram o sucesso profissional extrínseco e intrínseco com os traços de personalidade dos cinco fatores Five-Factor Model (FFM) e perceberam que os participantes mais jovens manifestaram maior disposição para a escolha de carreira em busca de maiores rendimentos e satisfação no trabalho. Abele e Spurk (2009) verificaram que o traço de personalidade de autoeficácia, medida nos estágios iniciais e após três anos de carreira, foi positivamente relacionada com salário e status. Os respondentes com mais de sete anos de carreira demonstraram um impacto positivo na mudança salarial e na satisfação profissional. Foi percebido ainda que as mulheres ganhavam menos do que os homens, mas não diferiam dos homens em status hierárquico e na satisfação profissional.

Quando se analisa os estudos que se debruçaram a investigar os interesses de carreira e o Dark Triad, instiga atenção a investigação de Schneider et al (2017) ao perceberem que as características grandiosidade, frieza emocional, manipulação e agressividade representaram uma previsão incremental que fornece oportunidades para interpretações mais ricas e precisas, em aplicação de pesquisas e aconselhamentos para se detectar a propensão de indivíduos em evidenciar os interesses de carreira.

Já Spurk et al. (2016) analisaram a relação entre o Dark Triad e o sucesso de carreira, objetivo e subjetivo, com jovens adultos que trabalham em uma indústria privada na Alemanha em fase inicial de carreira. $\mathrm{O}$ Narcisismo foi positivamente relacionado a salário. O Maquiavelismo se relacionou positivamente com status e satisfação profissional. Já a psicopatia foi negativamente relacionada a todos os indicadores analisados de sucesso profissional objetivo e subjetivo.

Nessa mesma perspectiva, Wakefield (2008) investigou a relação entre os traços de maquiavelismo e a escolha da carreira, satisfação no trabalho, satisfação profissional e ética ideológica e evidenciou que os contabilistas são significativamente menos maquiavélicos do que os grupos profissionais que participaram de estudos anteriores. Entretanto, os contabilistas mais maquiavélicos parecem estar menos satisfeitos com a contabilidade como carreira profissional e assumem uma postura ética relativista. O autor conclui que o comportamento maquiavélico não é necessário para se alcançar o sucesso na profissão contábil, mas os padrões éticos devem sustentar um alto nível de integridade em uma profissão caracterizada pelo idealismo. Nessa mesma perspectiva Qin e Xu (2013) perceberam uma baixa correlação negativa entre o maquiavelismo e salário, bem como ausência de associação com status e correlação negativa com a satisfação no trabalho.

No contexto dos interesses vocacionais, Jonason et al. (2014) estudaram os estilos realista, investigativo, artístico, social, empreendedor e convencional e os traços do Dark Triad. Comprovaram as hipóteses de que indivíduos com traço narcisista se interessam por carreiras artísticas, empreendedoras e sociais. Os psicopatas são mais interessados em carreiras realistas e práticas. Já os indivíduos maquiavélicos não se interessaram por empregos sociais, nem empreendedores. Os autores afirmam que os indivíduos ricos em traços do Dark Triad podem estruturar seu ambiente social através de preferências de carreiras idealizadas.

Nessa mesma perspectiva, Kowalski et al. (2017) investigaram como os interesses vocacionais, capturados por meio do instrumento de Jackson Career Explorer (JCE) (Schemer \& MacDougall. 2011), estão relacionados aos traços do Dark Triad. Verificaram que o narcisismo se apresentou positivamente correlacionado com os fatores de interesse artístico, social, biológico e comercial. A psicopatia foi positivamente correlacionada com interesses relacionados à ciência, à biologia e a transações comerciais; entretanto, não apresentou correlação com fatores sociais e estilo de trabalho. Já o Maquiavelismo esteve negativamente correlacionado com os fatores sociais e de estilo de trabalho.

Estudos que discutem o interesse pela escolha da carreira em contabilidade, examinaram a influência dos fatores extrínsecos (financeiros e relacionados ao trabalho) e intrínsecos (influência de pais e pessoas próximas). Os estudantes da Nova Zelândia dão maior importância a fatores financeiros e relacionados ao trabalho e relação benefício-custo percebido. Os fatores intrínsecos não influenciaram os estudantes em cursar contabilidade (Ahmed et al., 1997). Por outro lado, o estudo de Law (2010) não evidenciou que fatores financeiros, tal como recompensas financeiras, tenham correlação com a escolha de carreira de estudantes de contabilidade de Hong Kong. 
Auyeung e Sands (2010) estudaram os fatores da escolha da carreira em contabilidade, considerando a dimensão cultural Individualismo-Coletivismo para comparação relativa às escolhas de alunos de Hong Kong, Taiwan e Austrália. Os achados permitiram evidenciar que a influência dos pais, influência dos colegas, influência do professor e associação com outros no campo têm maior impacto nas escolhas de carreira para estudantes de Hong Kong e Taiwan, enquanto os estudantes australianos tendem a ser mais influenciados pela aptidão sobre os assuntos inerentes à contabilidade. Omar et al. (2015) verificaram que o salário inicial, a reputação do empregador e o ambiente de trabalho têm uma relação significativa com as preferências de seleção de trabalho na escolha de carreira de estudantes de contabilidade da Malásia.

Ao analisar estudos que relacionam o interesse de carreira contábil com personalidade, no aspecto educacional contábil, Holt . (2017) investigaram a influência das características de personalidade dos estudantes de contabilidade e o interesse de carreira na área de auditoria. Os autores observaram que aqueles que já possuem experiência na área têm maior propensão a preferirem atuar neste seguimento, sendo que estes estudantes têm um perfil de personalidade mais extrovertido, agradável e aberto à experiência.

Furnham . (2014) preferiram investigar traços sombrios de personalidade e medidas de valores e preferências que indicam as escolhas de carreira no ambiente de negócio. Os autores observaram que empresários com traços sombrios são atraídos por empregos empreendedores, sendo que, se os traços forem acentuados, podem conferir fracasso e descarrilamento das atividades. Os que defendem empregos sociais tendem a ser jovens e femininos. Eles tendem a ser maliciosos e ousados (como os empreendedores), são pouco diligentes e reservados, mas bastante imaginativos. Os indivíduos com traços sombrios não foram fortemente relacionados com empregos tradicionais.

Com base na revisão de literatura apresentada, elencou-se as seguintes hipóteses de pesquisa, considerando os fatores objetivos ou extrínsecos, subjetivos ou intrínsecos e características inerentes aos traços de personalidade que também estão interligados aos interesses de carreira:

H1: O Dark Triad tem menor influência sobre a escolha de carreira por fatores intrínsecos.

H2: O Dark Triad tem maior influência sobre a escolha de carreira por fatores extrínsecos.

H3: O Dark Triad influencia significativamente a escolha de carreira pela possibilidade de usar estratégias.

H4: O Dark Triad influencia significativamente a escolha de carreira pela possibilidade de manipulação.

H5: O Dark Triad influencia significativamente a escolha de carreira pela superioridade obtida.

H6: O Dark Triad influencia significativamente a escolha de carreira por exibicionismo.

H7: O Dark Triad influencia significativamente a escolha de carreira pela necessidade de poder.

As hipóteses H1 e H2 apoiam-se nos estudos de Judge et al. (1995), Spurk et al. (2016), Abelle e Spurk (2009), Sutin et al. (2009), Schneider et al. (2017). e outros apresentados. Já as hipóteses H3, H4, H5, H6 e H7 são sustentadas na teoria que evidencia as características dos traços de personalidade do Dark Triad reveladas nos estudos de Paulhus e Williams (2002), Jones e Paulhus (2014), Christie e Geis (1970), Raskin e Terry (1988) e Babiak e Hare (2006). Espera-se que os resultados confirmem as suposições e suporte a teoria.

\section{METODOLOGIA E CONSTRUTOS}

O estudo aplicou questionário para coleta de dados aplicado na modalidade presencial e on-line. Tal questionário é um típico 'autorrelato', que requer declarações ou respostas a uma série de perguntas, no qual as pessoas descrevem suas características em cada resposta (concordância ou discordância) quanto ao seu estado, sentimento ou crença. O questionário foi composto por: Termo de Consentimento Livre e Esclarecido (TCLE), Perfil demográfico e o Interesse de carreira de estudantes de contabilidade. A população do estudo é formada de alunos de Ciências Contábeis de universidades públicas e privadas. A amostra não probabilística selecionada por acessibilidade de 1.404 estudantes, está distribuída em cursos das diversas regiões do país, sendo 57\% dos estudantes oriundos de cursos do Nordeste, 33,2\% do Sudeste, 8,5\% do Sul, 1,2\% do Norte e 0,1\% do CentroOeste. Dentre os pesquisados $57,4 \%$ dos alunos cursam o bacharelado na rede pública, com maior incidência dos semestres letivos $2^{\circ}(12 \%), 7^{\circ}\left(12,2^{\%}\right)$ e $8^{\circ}(17,3 \%)$. O instrumento de coleta de dados está apresentado no Apêndice A. Cabe mencionar que o instrumento foi adaptado aos estudos brasileiros por meio de tradução reversa, após dois pré-testes realizados pelos estudos de D'Souza e Lima (2015) e D'Souza (2016). Estudo derivado dos autores da presente pesquisa foi aprovado pelo comitê de ética do Centro Universitário da Bahia, cujo número do Certificado de Apresentação para Apreciação Ética (CAAE) é 68742117.80000.0041. 
A principal variável do estudo, Dark Triad é a variável latente por ser a causa da Escolha de Carreira - variável observável. Segundo Weston (2006), as variáveis latentes influenciam as variáveis observáveis e são chamadas de construtos. As observáveis são coletadas por meio de um questionário e são influenciadas pela variável latente. A Figura 1 apresenta o desenho da pesquisa, detalhando o modelo conceitual.

Ressalta-se que as variáveis Remuneração, Prestígio Social, Posição Hierárquica, Disponibilidade de emprego, referem-se aos fatores objetivos ou extrínsecos, enquanto as variáveis, Vocação, Satisfação pessoal e profissional, Histórias de sucesso na família ou de amigos, referem-se aos fatores subjetivos ou intrínsecos, que serão testadas nas hipóteses H1 e H2. As variáveis Estratégia, Manipulação, Superioridade, Exibicionismo e Poder serão testadas pelas hipóteses H3, H4, H5, H6 e H7. Considera-se, ainda, as variáveis sociais como potencialmente influenciadoras das atitudes e perfis de personalidade.

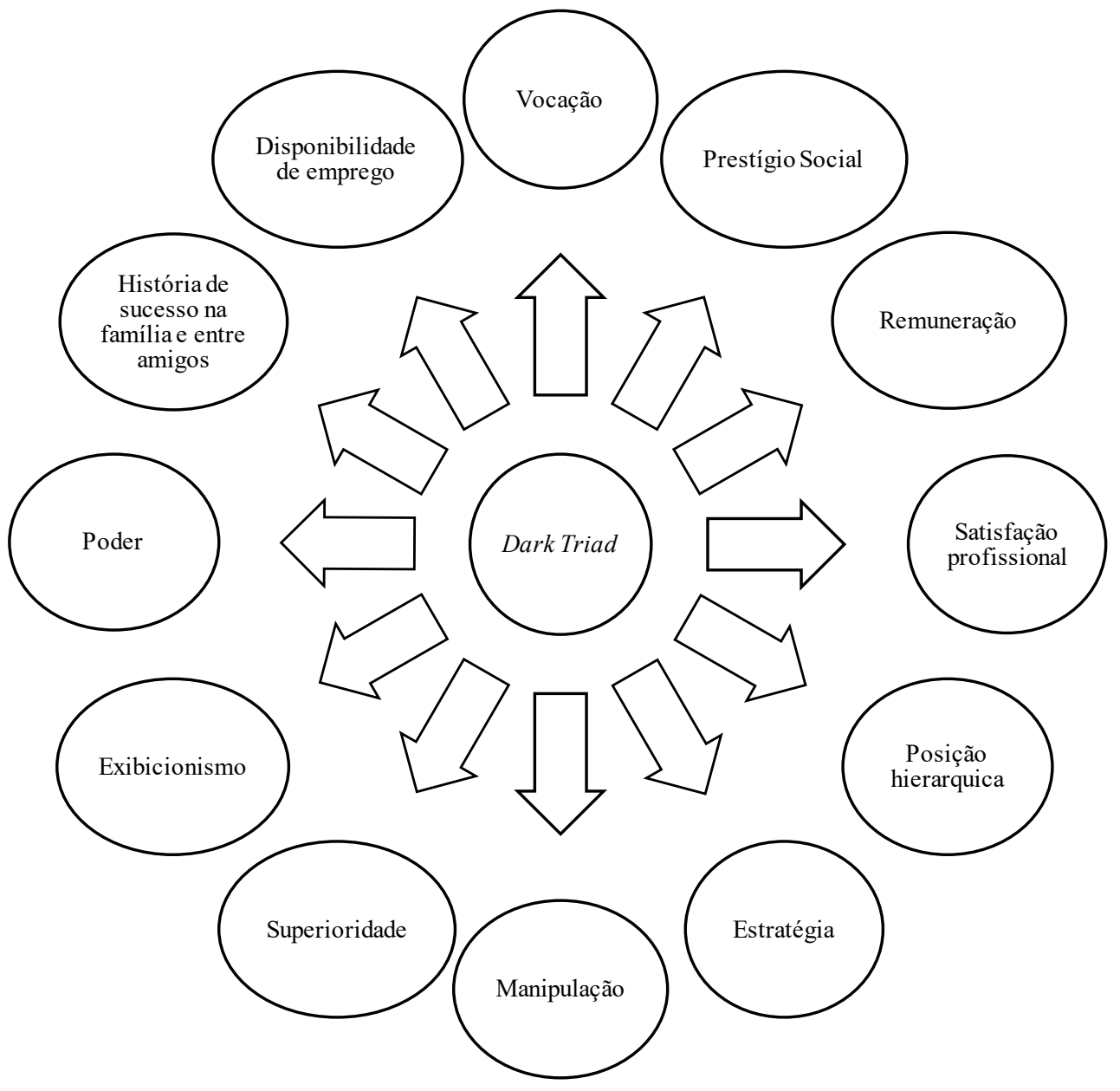

Figura 1. Dark Triad e variáveis para escolha de carreira

Fonte: Elaborado pelos autores.

\subsection{Mensuração do Dark Triad}

O Dark Triad foi mensurado por meio do Short Dark Triad (SD3) (Jones \& Paulhus, 2014), instrumento de medição de personalidade, composto de 27 assertivas, sendo 9 assertivas para cada traço, do tipo likert (1 a 7). A medida para cada um dos traços para cada indivíduo é a média da resposta likert para cada assertiva.

Em seguida, aplicou-se o Modelo de Equações Estruturais (MEE) para se comprovar a influência dessa variável, com base na teoria, ser a causa para o interesse de carreira dos estudantes de contabilidade. Segundo Hair Jr, Gabriel e Patel (2014), Weston (2006) e Chin (1998), o uso dessa técnica multivariada nas ciências sociais oportuniza maior flexibilidade do pesquisador para avaliar a interação entre teoria e dados e é utilizada quando se pretende observar a causa/efeito entre as variáveis, quando não se aplica o experimento como estratégia de coleta de dados. A especificação do modelo que indica quais relações são esperadas entre as variáveis deve ser uma condição observada antes da análise dos dados. 


\subsection{Mensuração de Interesse de Carreira}

Já para o levantamento do interesse de carreira, foram utilizadas questões do tipo likert $\left(\begin{array}{lll}1 & \text { a } & 7\end{array}\right)$ medindo o grau de concordância atitudinal dos estudantes, tomando por base aspectos objetivos ou extrínsecos (Remuneração, Prestígio Social, Posição Hierárquica, Disponibilidade de emprego) e subjetivos ou intrínsecos (Vocação, Satisfação pessoal e profissional, Histórias de sucesso na família ou de amigos) para as escolhas de carreira, com base nos estudos de Schneider et al.(2017). e Spurk et al. (2016). Em adição, foram incluídos aspectos que também são inerentes às características presentes nos traços de personalidade, conforme a revisão de literatura apresentada por Paulhus e Williams (2002) e Jones e Paulhus (2014) (Possibilidade de manipulação, Superioridade, Exibicionismo, Poder e o uso de estratégias).

Além dessas questões, indagou-se, por meio de uma questão de múltipla escolha, qual a profissão que mais despertou o interesse dos estudantes de contabilidade, dentre estas: Auditoria, Perícia, Contabilidade em instituições privadas, Contabilidade de instituições públicas, Controladoria, Consultoria, Docência, Pesquisa, Nenhuma ou Outra profissão não elencada.

\subsection{Abordagem estatística}

Aplicamos o Modelo de Equações Estruturais (MEE) do tipo confirmatória CB-SEM para observar a relação associativa entre os construtos, por meio de um modelo unidimensional para amostras maiores que 200 participantes (Hair Jr. et al., 2014; Weston, 2006). Os testes foram rodados no software AMOS, incluindo a visualização do modelo, as estimativas e o diagrama de caminhos, que evidencia o peso de cada variável observável. A MEE é a fusão da análise fatorial com a análise do caminho (Lee, Petter, Fayard e Robinson, 2011) e permite avaliar, simultaneamente, o modelo de mensuração (tradicionalmente realizado com análise fatorial) e o modelo estrutural (tradicionalmente realizado com análise do caminho). A técnica tem sido utilizada por estudos em contabilidade com o propósito de analisar associação entre construtos (ex. Lau \& Roopnarain, 2014; Nicolaou, Sedatole, \& Lankton, 2011; Elbashir, Collier, \& Sutton, 2011; Hartmann \& Slapničar, 2009).

\section{AMOSTRA}

A amostra reuniu 1.404 respostas de estudantes de graduação em Ciências Contábeis em todo país, incluindo universidades públicas e privadas, com 58,8\% participantes do gênero feminino e maior prevalência da faixa etária entre 17 e 25 anos (61,5\%). Apenas uma menor parte dos estudantes têm pais com o ensino médio completo (33,5\%). A maioria dos estudantes já exerceu ou exerce atividade remunerada $(85,5 \%)$. A renda familiar (em cerca de $50 \%$ dos casos) está entre dois e quatro salários mínimos. O estudo foi realizado nas cinco regiões brasileiras, com maiores participações nas regiões 57\% do Nordeste e 33,2\% do Sudeste.

Ao questionar os estudantes sobre quais carreiras em contabilidade eles se sentiam mais interessados em seguir, os maiores destaques foram: Auditoria 28,2\% e Contabilidade em organizações privadas 24,4\%, sendo a Pesquisa $0,6 \%$ a menos selecionada, conforme apresentado no histograma da Figura 2. Na amostra do estudo de Dalton, Buchheit e McMillanos (2014), os estudantes de contabilidade que planejam prosseguir carreiras em auditoria acreditam que terão mais interação com clientes, melhores oportunidades de trabalho futuro e maior conhecimento sobre o processamento de negócios. Em contrapartida, os estudantes de contabilidade que planejam prosseguir carreiras da área contábil fiscal, percebem que terão uma rotina diária mais estável, desenvolverão habilidades mais especializadas e relacionamentos de clientes de forma mais colaborativa. Já na amostra de Holt et al. (2017), os estudantes que escolheram atuar em Auditoria, tinham perfis mais extrovertidos, agradáveis e abertos à experiência

$\mathrm{Na}$ amostra analisada, o traço de Maquiavelismo foi o que apresentou a maior média $(3,56)$, corroborado por estudos estrangeiros (Jones \& Paulhus, 2014) e nacionais (D’Souza, Lima, Jones, \& Carré, 2018). Os maiores níveis de concordância dos estudantes para os traços maquiavélicos foram as assertivas: M1 "não é prudente contar meus segredos”, M7 “existem coisas que eu escondo de outras pessoas porque elas não precisam saber" e M4 "evito o conflito direto com os outros porque podem ser úteis no futuro". Isso sugere maior inclinação dos estudantes para atitudes de manipulação, uso de estratégia, busca de reputação e poder. Coloca-se esta reflexão tendo em vista o nível dessas características, sobretudo quando se analisa as consequências da manipulação na área contábil evidenciada nos escândalos financeiros e fraudes em relatórios contábeis. O mesmo se vê nos estudos de D'Souza, Aragão, e De Luca (2018) que evidenciaram, através da tessitura do discurso dos relatórios da administração da OAS S.A. e Odebrecht S.A., o ethos narcisista e maquiavélico dos líderes por meio da semântica das expressões e atos de fala que sugerem características maquiavélicas e narcisistas sobrepostas. 
Carreira

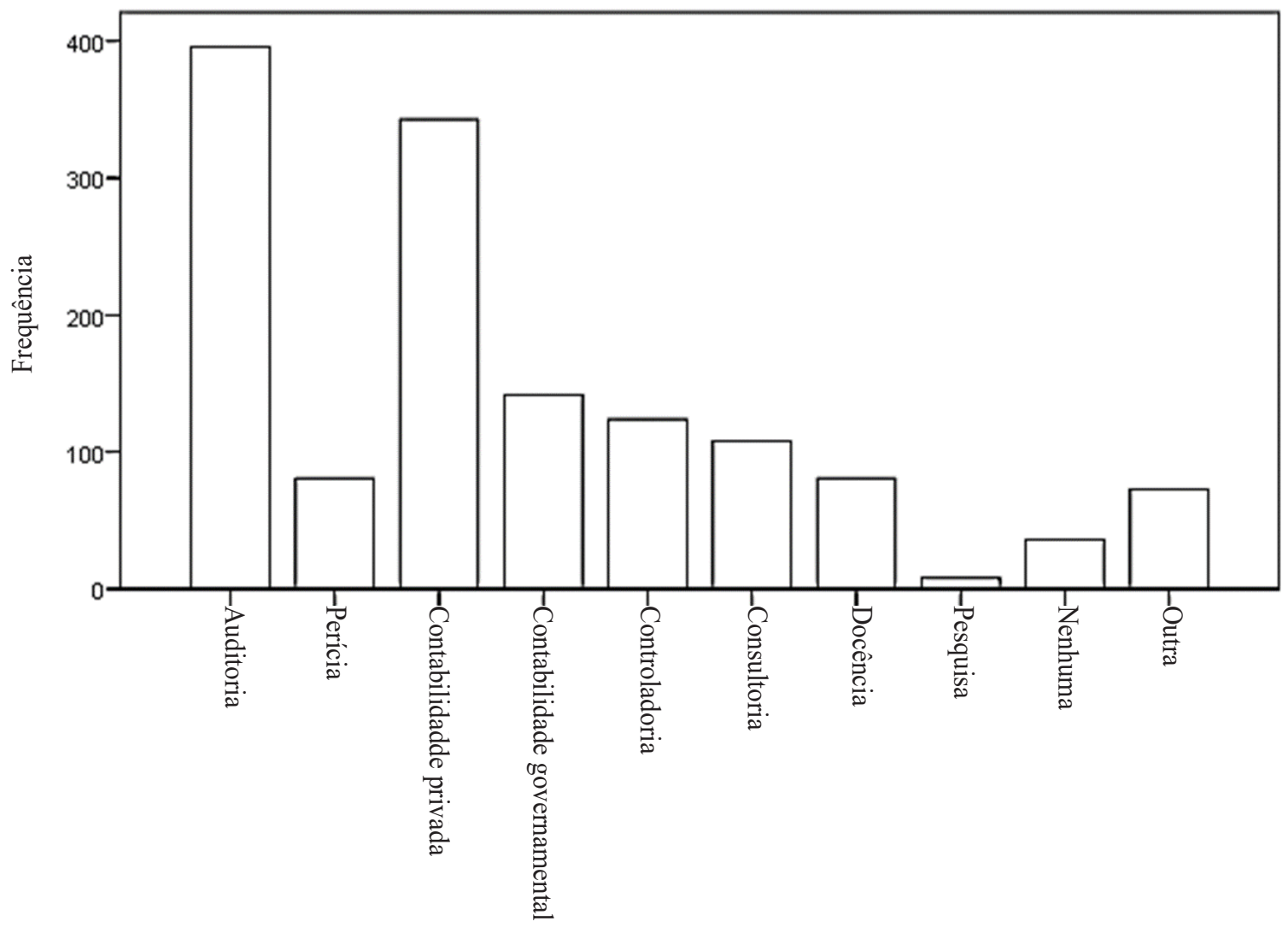

Figura 2. Carreiras pretendidas pelos estudantes de contabilidade

Fonte: Elaborado pelos autores.

Para o traço narcisista as maiores concordâncias foram as assertivas N9 "eu insisto em receber o respeito que mereço" e N5 "Eu gosto de conhecer pessoas importantes". Isso denota maior propensão dos estudantes para características de superioridade, vaidade e exibicionismo, peculiares aos traços narcisistas. Se, por um lado, essas características podem motivar maior empenho para o alcance dos resultados empresariais, pode também revelar, em um nível exagerado, a concordância em humilhar os colegas, em impor e até fraudar resultados para bater metas e ser aplaudido para alimentar o ego. Avelino, Lima, Cunha e Colauto (2017) quando investigaram sobre traços narcisistas com estudantes de contabilidade brasileiros, perceberam concordância sobre serem indivíduos de sucesso, bons líderes e que gostam de se olhar no espelho.

Quando se analisou a predisposição do traço da Psicopatia, observou-se maior concordância para as assertivas: P2 "eu evito situações perigosas" e P6 "as pessoas que aprontam comigo sempre se arrependem". Aqui se observa a ausência de remorso em revidar com as pessoas e a insensibilidade, que podem provocar conflitos e um clima não salutar entre os colegas no meio acadêmico e organizacional. 
Tabela 1. Média, Mediana, desvio padrão, mínimo e máximo dos traços do Dark Triad e de todas as variáveis de pesquisa incluídas no modelo

\begin{tabular}{|c|c|c|c|c|c|}
\hline Variáveis da Pesquisa & Mínimo & Máximo & Média & Mediana & $\begin{array}{l}\text { Desvio } \\
\text { padrão }\end{array}$ \\
\hline \multicolumn{6}{|c|}{ Características sociais e demográficas } \\
\hline Gênero (1 para masculino) & 0 & 1 & 0,41 & 0 & 0,492 \\
\hline Semestre em curso & 1 & 11 & 5.15 & 5 & 2,733 \\
\hline Exerce atividade remunerada & 0 & 1 & 0,85 & 1 & 0,353 \\
\hline Faixa etária & 1 & 4 & Ver frequência no apêndice & & \\
\hline Escolaridade dos pais & 1 & 9 & Ver frequência no apêndice & & \\
\hline Região do curso & 1 & 5 & Ver frequência no apêndice & & \\
\hline Renda familiar & 1 & 5 & Ver frequência no apêndice & & \\
\hline \multicolumn{6}{|c|}{ Interesses de Carreira } \\
\hline Vocação & 1 & 7 & 4,68 & 5 & 1,740 \\
\hline Prestigio & 1 & 7 & 4,07 & 4 & 1,852 \\
\hline Remuneração & 1 & 7 & 5,21 & 5 & 1,612 \\
\hline Satisfação profissional & 1 & 7 & 5,54 & 6 & 1,654 \\
\hline Posição de Liderança & 1 & 7 & 4,53 & 5 & 1,861 \\
\hline Estratégia & 1 & 7 & 4,77 & 5 & 1,869 \\
\hline Manipulação & 1 & 7 & 2,52 & 2 & 1,870 \\
\hline Superioridade & 1 & 7 & 2,85 & 2 & 1,921 \\
\hline Exibicionismo & 1 & 7 & 1,94 & 1 & 1,536 \\
\hline Poder & 1 & 7 & 2,03 & 1 & 1,593 \\
\hline História da Família & 1 & 7 & 3,14 & 2 & 2,282 \\
\hline Disponibilidade de Emprego & 1 & 7 & 3,60 & 4 & 2,144 \\
\hline \multicolumn{6}{|c|}{ Dark Triad } \\
\hline Maquiavelismo & 1 & 7,00 & 3,55 & 3,6 & 1,079 \\
\hline Narcisismo & 1 & 6,90 & 3,49 & 3,6 & 0,894 \\
\hline Psicopatia & 1 & 6,70 & 2,14 & 2,0 & 0,841 \\
\hline
\end{tabular}

Fonte: Elaborado pelos autores

Nota: Parametrização das variáveis sócias e demográficas no Apêndice B.

Quanto aos interesses de carreira, a satisfação profissional e a remuneração obtiveram maiores médias (5,21 e 5,54 respectivamente). Os estudantes anseiam pela realização nas atividades escolhidas, motivados também pela retribuição pecuniária. Esse achado confirma que a remuneração é uma das forças que movem os indivíduos ao empenho necessário para o alcance de metas que lhes trarão uma boa imagem perante a empresa e também a possibilidade de recompensas adicionais como as bonificações.

Analisamos em seguida a diferença de médias entre os traços do Dark Triad e as carreiras mais escolhidas pelos estudantes e as variáveis sociais e demográficas: gênero, faixa etária, atividade remunerada e a região (Tabela 2). As carreiras de Auditoria e Contabilidade em organizações privadas não apresentam diferenças entre as médias, indicando que as características presentes nos traços do Maquiavelismo, Narcisismo e Psicopatia não influenciariam na carreira pretendida pelos aspirantes à profissão.

O gênero apresenta diferença para os três traços de personalidade. Na presente amostra os homens são mais maquiavélicos (média=3,784), narcisistas (média=3,589) e psicopatas sociais (média=2,311). Estes resultados se assemelham com amostras similares de estudantes. Sobre os traços narcisistas, estudos brasileiros como o de Lima, Souza, e D’Souza (2016), observaram que o gênero masculino é mais narcisista. Contudo, D’Souza, Oliveira, Almeida, e Natividade (2018) e Avelino e Lima (2017) não encontraram essas diferenças de traço narcisista para estudantes brasileiros de administração e contabilidade. Ao analisar os três traços com estudantes croatas, Bogdanovic e Cingula (2015) perceberam que o gênero masculino apresentou maior escore de maquiavelismo e psicopatia, sem efeito para o narcisismo. 
Tabela 2. Testes não paramétricos: Dark Triad e fatores sociais Mann-Whitney: DL e DF

\begin{tabular}{rlccc}
\hline & Teste & Maquiavelismo & Narcisismo & \multicolumn{2}{c}{ Psicopatia } \\
\cline { 3 - 4 } & & Sig & Sig & Sig \\
\hline Gênero (masculino=1) & Mann-Whiney & $0,000(* *)$ & $0,001(* *)$ & $0,000(* *)$ \\
Faixa etária & Kruskal-Wallis & $0,000(* *)$ & $0,010(* *)$ & 0,062 \\
Atividade Remunerada & Mann-Whiney & $0,001(* *)$ & 0,647 & 0,143 \\
Região do curso & KrusKal-Wallis & $0,004(* *)$ & 0,339 & 0,318 \\
Auditoria & Mann-Whiney & 0,312 & 0,462 & 0,159 \\
Contabilidade Privada & Mann-Whiney & 0,404 & 0,143 & 0,948 \\
\hline
\end{tabular}

Fonte: Elaborado pelos autores.

Nota: $(* *) \mathrm{p}<0,05$

Os traços do Narcisismo e do Maquiavelismo também se diferenciaram na presença da faixa etária. Os estudantes com idade acima de 45 anos são mais narcisistas (média=3,803), sugerindo que com aumento da idade os traços se intensificam. Avelino e Lima (2017) não encontraram diferenças no estudo com estudantes brasileiros. Já Akers, Giacomino e Weber (2014) observaram que os profissionais americanos mais jovens que atuam em empresas de contabilidade pública são mais narcisistas que os com maior idade.

Já para os traços de Maquiavelismo, os estudantes entre 17 e 25 anos (média=3,643), apresentaram maiores predisposição para a manipulação e estratégia. Sobre a atividade remunerada, aqueles quem ainda não estão em atividade laboral apresentaram maior predisposição para os traços maquiavélicos (média=3,784). Por fim, as regiões apresentam distintas intensidades em traços de Maquiavelismo, especialmente pela diferença de cultura e oportunidades. O Centro-oeste (média=2,250) aparece como a localidade em que os estudantes apresentaram traços mais intensos. Observa-se, portanto que a predisposição maquiavélica se evidencia de forma mais preponderante nas variáveis analisadas, o que sugere habilidade de manipulação, uso de estratégias e busca por poder.

\section{ANÁLISE E DISCUSSÃO DOS RESULTADOS}

Dada a distribuição normal dos dados, aplicou-se o MEE baseado na covariância para a análise confirmatória da associação entre a variável latente exógena Dark Triad e a variável observável interesse de carreira. Todas as variáveis de interesse de carreira foram inseridas e nenhuma delas foi excluída do modelo, por se apresentarem significativas a $(\mathrm{p}=, 01)$ (Tabela 3). O coeficiente de confiabilidade Alpha de Cronbach de 0,823 indica a consistência do modelo.

Tabela 3. Significância das variáveis

\begin{tabular}{|c|c|c|c|c|c|c|}
\hline & & & Estimativa & S.E. & C.R. & $\mathbf{P}$ \\
\hline Vocação & $<--$ & Dark_Triad & 0,330 & 0,050 & 6,662 & $* * *$ \\
\hline Prestigio & $<---$ & Dark_Triad & 0,829 & 0,050 & 16,426 & $* * *$ \\
\hline Remuneração & $<---$ & Dark_Triad & 0,309 & 0,046 & 6,723 & $* * *$ \\
\hline Satisfação profissional & $<---$ & Dark_Triad & 0,300 & 0,047 & 6,423 & $* * *$ \\
\hline Posição hierárquica & $<---$ & Dark_Triad & 0,895 & 0,050 & 17,962 & $* * *$ \\
\hline Estratégia & $<--$ & Dark_Triad & 0,850 & 0,052 & 16,323 & $* * *$ \\
\hline Manipulação & $<---$ & Dark_Triad & 1,432 & 0,045 & 31,722 & $* * *$ \\
\hline Superioridade & $<---$ & Dark_Triad & 1,541 & 0,046 & 33,769 & $* * *$ \\
\hline Exibicionismo & $<---$ & Dark_Triad & 1,185 & 0,038 & 31,473 & $* * *$ \\
\hline Poder & $<---$ & Dark_Triad & 1,176 & 0,040 & 29,603 & $* * *$ \\
\hline História de sucesso na família & $<---$ & Dark_Triad & 0,736 & 0,064 & 11,536 & $* * *$ \\
\hline Disponibilidade de emprego & $<---$ & Dark_Triad & 0,710 & 0,060 & 11,857 & $* * *$ \\
\hline
\end{tabular}

Fonte: Elaborado pelos autores.

Nota: $* * * \mathrm{p}<0,01$ 
Os resultados do modelo não apresentaram parâmetros aceitáveis pelas referências propostas por Weston (2006). Então se procedeu ao ajuste, inicialmente pela correlação entre os erros associados às variáveis de um mesmo construto. O ajuste, também chamado de modificação, trouxe os erros que deviam ser correlacionados (Tabela 4). O modelo 2 apresentou bons resultados para o teste qui-quadrado $(\chi 2)=150,110$, para o índice de ajuste comparativo $\mathrm{CFI}=0,983$ e para a raiz do erro quadrático médio de aproximação RMSEA=0,052. Este último é uma medida reconhecida como um dos melhores critérios informativos para ser utilizado em modelagem de equações estruturais e para todos os outros parâmetros de ajustes considerados alternativos (Tabela 4). A probabilidade de significância para todos os coeficientes foi de $(\mathrm{p}=, 000)$, permitindo a continuidade da análise do modelo de MEE. Essa prática é recorrente na literatura e foi realizada por estudos na área contábil e de negócios, tais como Hair Jr et al. (2014) e Gonzalez (2016).

Tabela 4. Parâmetros comparados do Modelo Ajustado

\begin{tabular}{rcccc}
\hline \multicolumn{1}{c}{ Parâmetros } & Referências & $\begin{array}{c}\text { Modelo Base } \\
\mathbf{( p = 0 , 0 0 0 )}\end{array}$ & $\begin{array}{c}\text { Modelo 1 } \\
(\mathbf{p}=\mathbf{0 , 0 0 0})\end{array}$ & $\begin{array}{c}\text { Modelo 2 } \\
\mathbf{( p = 0 , 0 0 0 )}\end{array}$ \\
\hline Qui-quadrado $(\chi 2)$ & Menor melhor & 2760,813 & 346,627 & 150,110 \\
CMIN/DF & Até 5. Menor melhor & 51,126 & 9,368 & 4,842 \\
GFI & Acima de 0,9. Maior melhor & 0,680 & 0,959 & 0,983 \\
AGFI & Acima de 0,9. Maior melhor & 0,538 & 0,913 & 0,956 \\
CFI & Acima de 0,9. Maior melhor & 0,597 & 0,954 & 0,982 \\
RMSEA & Entre 0,05 e 0,1. Bom abaixo de 0,08 & 0,189 & 0,077 & 0,052 \\
AIC & Menor melhor & $2.808,313$ & 428,627 & 244,110 \\
CAIC & Menor melhor & $2.958,79$ & 684,758 & 537,723 \\
RMR padronizado & 0,05 & 0,1474 & 0,0638 & 0,36 \\
\hline
\end{tabular}

Fonte: Elaborado pelos autores.

Nota: Minimun Discrepancy (CMIN); Goodnes of Fit Index (GFI), Adjusted Goodness of Fit Index (AGFI); Comparative of Fit Index (CFI); Steiger's Root Mean Square (RMSEA), Standardized Root Mean Square Residual (SRMR); Akaike Information Criterion (AIC) e Consistent Akaike Information Criterion (CAIC); Root Mean-square Residual (RMR).

O diagrama de caminhos (Figura 3) mostra o sistema de equações simultâneas e as correlações aos parâmetros do modelo (Bistaffa, 2010). O Dark Triad tem influência direta sobre todas as variáveis de Interesse de Carreira incluídas no modelo, o que suporta todas as hipóteses formuladas neste estudo. 


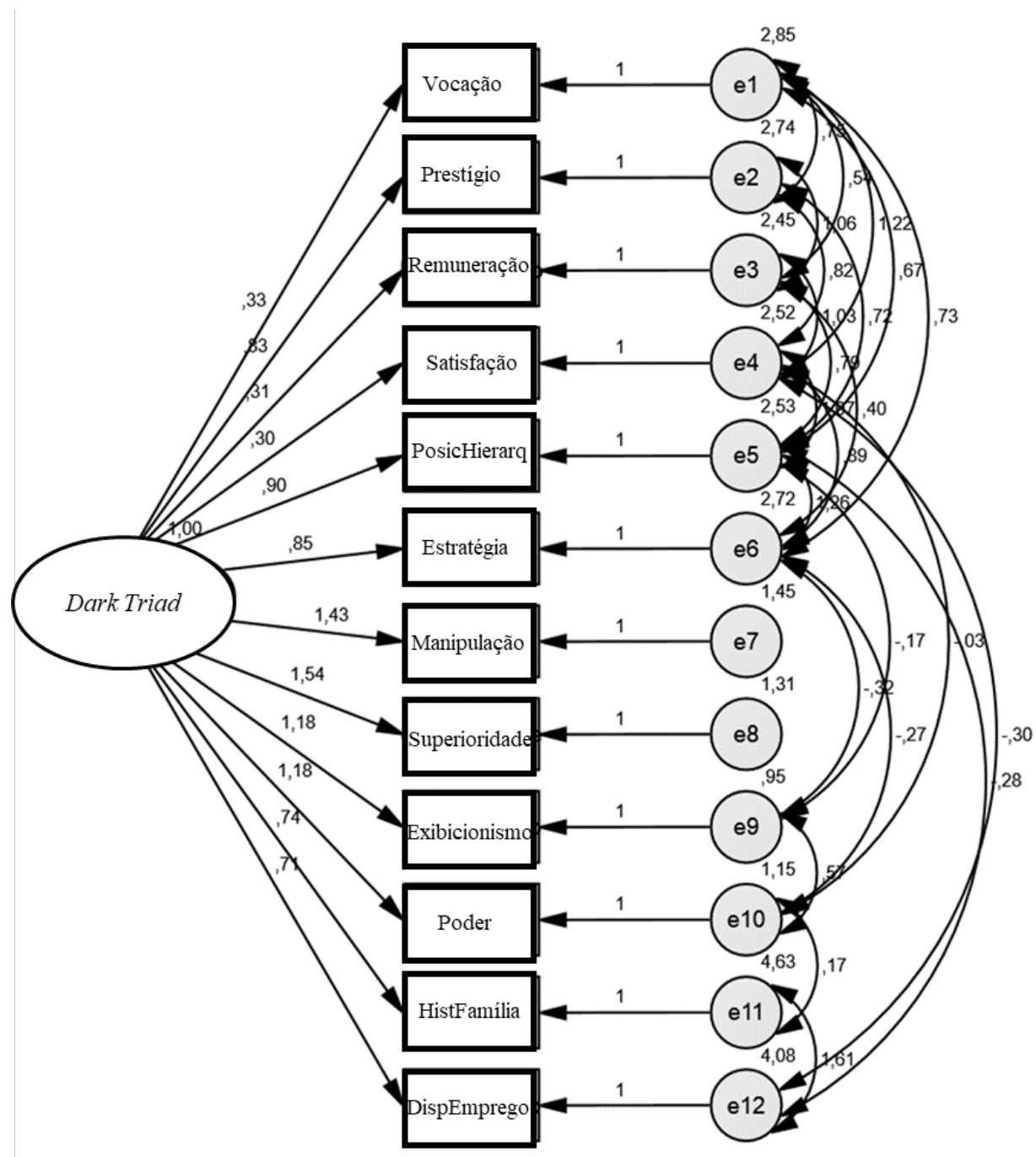

Figura 3. Diagrama de Caminhos

Fonte: Elaborado pelos autores.

Nota: O peso de cada variável observável $* * * \mathrm{p}<0.01$. A variância residual dos componentes (erro das variâncias) indica a quantidade de variáveis não explicadas. Assim, para cada variável observável: R2 = (1- erro da variância). PosicHierarq: Posição Hierárquica; HistFamilia: História de sucesso na família; DispEmprego: Disponibilidade de emprego.

Ao analisar o diagrama, observa-se que o Dark Triad tem relação com as escolhas de carreira pelos estudantes de contabilidade da amostra, potencialmente pelo interesse em serem Superiores $(1,54)$ em relação aos outros, pela possibilidade de Manipulação $(1,43)$, pela possibilidade de se Exibirem $(1,18)$, pelo anseio de Poder $(1,18)$, pela possibilidade de exercer posições hierárquicas elevadas $(0,90)$, pela possibilidade de usar Estratégias $(0,85)$ para conseguir seus objetivos, pela obtenção de Prestígio $(0,83)$, status e reputação no ambiente laboral, pela História de sucesso na família e pessoas próximas como amigos $(0,74)$ e pela Disponibilidade de emprego $(0,71)$. Tais interesses estão associados às maiores influências dos traços do Dark Triad, pelo peso refletido no teste.

Esse resultado corrobora a teoria dos traços de personalidade do Dark Triad, sobretudo pelo interesse por Manipulação, Prestígio, busca de Poder, Status, busca de Posições hierárquicas, propósitos comuns aos três traços (Jones \& Paulhus, 2014). O Exibicionismo e a Superioridade são características marcantes de indivíduos narcisistas (Raskin \& Terry, 1988; Chatterjee \& Hambrick, 2011; Maccoby, 2004), e a Estratégia como ferramenta essencial para as atitudes de indivíduos maquiavelistas (Jones \& Figueredo, 2013). Os estudos de Schneider et al. (2017) também perceberam que as características superioridade e manipulação representam uma previsão incremental que fornece oportunidades para interpretações mais ricas e precisas, em pesquisas que se debruçam a estudar personalidade e carreira. 
Para o indicador Histórico de sucesso familiar, esperava-se uma menor influência do Dark Triad, sobretudo pelas atitudes insensíveis e de ausência de afabilidade exteriorizadas pelos indivíduos ricos desses traços. Os estudos de Auyeung e Sands (2010) também evidenciaram o histórico familiar e influência de pessoas próximas, como interesse na escolha de carreira de estudantes de Hong Kong e Taiwan, resultado não convergente com os de Ahmed et al. (1997) que aplicaram a pesquisa com estudantes da Nova Zelândia.

Já as variáveis Satisfação profissional, Remuneração e Vocação apresentaram os menores pesos $(0,30)$, $(0,31),(0,33)$, respectivamente, e consequentemente, menor efeito da variável latente, embora a influência dos traços do Dark Triad esteja presente em função do nível de significância $(p=, 00)$ para esses indicadores. Os resultados sobre os indicadores Satisfação profissional e Vocação eram esperados, pela insensibilidade dos traços de personalidade.

A Remuneração, que surpreende por não ser um dos principais fatores, é influenciada pelo Dark Triad indicando o efeito a ambição por riqueza e poder de salários e recompensas de uma carreira, que podem até induzir a manipular ou fraudar resultados. Os resultados são convergentes com os estudantes de Hong Kong em Law (2010), que analisou objetivos individuais em manipular para obter maiores recompensas financeiras, e com Hsiao e Casa Nova (2016), Omar et al. (2015), Abele e Spurk (2009), Ahmed et al. (1997), em que o salário é um dos principais interesses extrínsecos de interesse de carreira.

Ao comparar com estudos em ambientes laborais que investigaram os traços de personalidade do Dark Triad, Spurk et al. (2016) comprovaram a correlação do Narcisismo com salário. O Maquiavelismo foi associado a status e satisfação profissional. Já a psicopatia foi negativamente relacionada a todos os indicadores analisados de sucesso profissional objetivo e subjetivo. Segundo Wakefield (2008), os contabilistas mais maquiavélicos parecem estar menos satisfeitos com a contabilidade, enquanto que Qin e Xu (2013) perceberam uma correlação negativa entre o maquiavelismo e salário, ausência de associação com status e correlação negativa com a satisfação no trabalho. Diante dos resultados apresentados, reitera-se a influência significativa do Dark Triad, em maior ou menor grau, para todas as variáveis de interesses de carreira inseridas no modelo, suportando as hipóteses H1, H2, H3, H4, H5, H6 e H7.

\section{CONCLUSÕES}

Uma das principais vertentes do estudo de interesses de carreira é o sucesso (Abele \& Spurk, 2009). Os resultados do estudo aplicado com 1.404 estudantes brasileiros de contabilidade revelaram que a Auditoria, seguida da Contabilidade em organizações privadas, foram as carreiras que mais despertaram interesse dos estudantes como aspiração profissional. A Satisfação profissional e a Remuneração foram os motivos de escolha de carreira com maiores médias de aceitação. Os estudantes consideram que não é prudente contar seus segredos, escondem algumas informações de outras pessoas, porque elas não precisam saber e evitam o conflito direto com os outros, porque podem ser úteis no futuro. Essas características remetem a traços maquiavélicos que têm por núcleo características como preocupação com a reputação e o uso de estratégia para alcance de objetivos próprios.

Os achados também evidenciaram maior predisposição dos estudantes em insistirem em receberem o respeito que merecem e o gosto em conhecer pessoas importantes. Essas características remetem aos traços narcisistas marcados pela autoestima, vaidade, egoísmo e autoridade. A predisposição dos estudantes à psicopatia aparece quando evitam situações perigosas e pelo sentimento de vingança, impulsividade e ausência de culpa e remorso, pois "dão o troco às pessoas que aprontam com eles e não se arrependem".

Na amostra analisada, o Dark Triad tem influência direta, em maior ou menor grau, sobre todas as variáveis de Interesse de Carreira, e portanto, influenciam os estudantes na escolha das carreiras da área contábil. Esta escolha tem em si a busca por serem superiores, se exibirem e alcançarem o desejado prestígio social ao assumirem posições de alto nível hierárquico. Essa busca por poder também é movida pela história de sucesso na família ou amigos.

Aparecerem em menor grau de influência, a satisfação profissional, vocação e remuneração. Nesse particular, surpreendeu a menor influência dos traços do Dark Triad para a escolha de carreira por remuneração, especialmente porque indivíduos ricos de características desses três traços são ambiciosos e buscam o poder a qualquer custo, o que levaria ao anseio por maiores salários e recompensas no ambiente laboral.

A pesquisa pretendeu suscitar a reflexão sobre implicações práticas nas atitudes de estudantes e futuros profissionais que tenham predisposição aos traços de personalidade sombria e chamar a atenção de recrutadores corporativos, gestores acadêmicos, professores e os próprios estudantes de contabilidade. 
Indivíduos com fortes traços do Dark Triad podem exteriorizar atitudes que trazem consequências prejudiciais ao meio acadêmico, laboral e à sociedade como um todo. Entretanto, como defende D'Souza, Lima, Jones e Carré (2018), esses traços de intensidade moderada podem revelar talentos, criatividade, inovação e melhores desempenhos individuais e empresariais; portanto também podem ser benéficos. Assim, para futuras pesquisas, sugere-se a análise do lado brilhante dos traços de personalidade, como afirma Volmer et al. (2016), nos interesses de carreira, que podem ser refletidos nas atitudes dos estudantes de contabilidade.

\section{REFERÊNCIAS}

Abele, A. E., \& Spurk, D. (2009). The longitudinal impact of self-efficacy and career goals on objective and subjective career success. Journal of Vocational Behavior, 74(1), 53-62. DOI: https://doi.org/10.1016/j. jvb.2008.10.005.

Agarwala, T. (2008). Factors influencing career choice of management students in India. Career Development International, 13(4), 362-376. DOI: https://doi.org/10.1108/13620430810880844.

Ahmed, K., Alam, K. F., \& Alam, M. (1997). An empirical study of factors affecting accounting students' career choice in New Zealand. Accounting Education, 6(4), 325-335. DOI: https://doi.org/10.1080/096392897331398.

Akers, M. D.; Giacomino, D. E., \& Weber, J. (2014). Narcissism in Public Accounting Firms. Accounting and Finance Research, 3(3), 170-178. DOI: https://doi.org/10.5430/afr.v3n3p170.

Auyeung, P., \& Sands, J. (1997). Factors influencing accounting students' career choice: a cross-cultural validation study. Accounting Education, 6(1), 13-23. DOI: https://doi.org/10.1080/096392897331596.

Avelino, B. C., Lima, G. A. S. F., Cunha, J. V. A., Colauto, R. D. (2017). The Influence of Narcissism in the Professional Environment: Aspects Related to Dishonesty. ASAA JOURNAL - Advances in Scientific and Applied Accounting, 10(3), 334-356. DOI: http://dx.doi.org/10.14392/asaa.2017100306.

Avelino, B. C.; Lima, G. A. S. F. de. (2017). Narcisismo e desonestidade acadêmica. Revista Universo Contábil, 13(3), p. 70-89. DOI: http://dx.doi.org/10.4270/RUC.2017319.

Babiak, P., \& Hare, R. D. (2006). Snakes in suits: when psychopaths go to work. New York: Harper Collins Publishers Inc.

Babiak, P., Neumann, C., \& Hare R. D. (2010). Corporate psychopathy: talking the walk. Behavioral Sciences and the Law, 28(2), 174-193. DOI: https://doi.org/10.1002/bsl.925.

Berg, J. M., Lilienfeld, S. O., \& Waldman, I. D. (2013). Bargaining with the devil: using economic decisionmaking tasks to examine the heterogeneity of psychopathic traits. Journal of Research in Personality, 7, 472482. DOI: https://doi.org/10.1016/j.jrp.2013.04.003.

Beynon, J., Toohey, K., \& Kishor, N. (1998). Do visible minority students of chinese and south asian ancestry want teaching as a career? Perceptions of some secondary school students in Vancouver, BC. Canadian Ethnic Studies Journal, 30(2), 50-75.

Bistaffa, B. C. (2010). Incorporação de indicadores categóricos ordinais em modelos de equações estruturais. Dissertação de Mestrado, Instituto de Matemática e Estatística, Universidade de São Paulo, São Paulo, SP, Brasil.

Boddy, C. R. (2009). Corporate psychopaths in Australian workplaces: their influence on organizational outcomes. Perth, Australia: Curtin University of Technology.

Boddy, C. R. (2010). Corporate psychopaths and organizational type. Journal of Public Affairs, 10(4), $300-312$. DOI: https://doi.org/10.1002/pa.365.

Boddy, C. R. (2011). Corporate psychopaths, bullying and unfair supervision in the workplace. Journal of Business Ethics, 100, 367-379. DOI: https://doi.org/10.1007/s10551-010-0689-5.

Bogdanovic, M., \& Cingula, D. (2015). Dark triad of croatian management students. Central European Business Review, (4), 30-47.

Campbell, W. K., Bush, C. P., Brunell, A. B., \& Shelton, J. (2005). Understanding the social costs of narcissism: the case of the tragedy of the commons. Society for Personality and Social Psychology, 31(10), 1.358-1.368. DOI: https://doi.org/10.1177/0146167205274855. 
Campbell, W. K., Goodie A. S., \& Foster, J. D. (2004). Narcissism, confidence, and risk attitude. Journal of Behavioral Decision Making, 17(4), 297-311. DOI: https://doi.org/10.1002/bdm.475.

Campbell, W. K., Hoffman, B. J., Campbell, S. M., \& Marchisio, G. (2011). Narcissism in organizational contexts. Human Resource Management Review, 21(4), 268-284. DOI: https://doi.org/10.1016/j.hrmr.2010.10.007.

Carpenter, P., \& Foster, B. (1977). The career decisions of student teachers. Educational Research and Perspectives, $4(1), 23-33$.

Chatterjee, A. \& Hambrick, D. C. (2011). Executive personality, capability cues, and risk taking: how narcissistic CEOs react to their successes and stumbles. Administrative Science Quarterly, 56(2), 202-237. DOI: https:// doi.org/10.1177/0001839211427534.

Chatterjee, A., \& Hambrick. D. C. (2007). It's all about me: narcissistic chief executive officers and their effects on company strategy and performance. Administrative Science Quarterly, 52(3), 351-386. DOI: https://doi. org/10.2189/asqu.52.3.351.

Chin, W. W. (1998). Issues and opinion on structural equation modeling. MIS Quarterly, 22 (1):7-16.

Christie, R., \& Geis, F. L. (1970). Studies in machiavellianism. New York: Academic Press.

Corzine, J. B. (1997). Machiavellianism and management: a review of single-nation studies exclusive of the USA and cross-national studies. Psychological Reports, 80(1), 291-304. DOI: https://doi.org/10.2466/ pr0.1997.80.1.291.

D’Souza, M. F., Lima, G. A. S. F. de, Jones, D. N., \& Carré, Jessica R. (2018). Eu ganho, a empresa ganha ou ganhamos juntos? Traços moderados do Dark Triad e a maximização de lucros. Revista Contabilidade \& Finanças, 30(79), 123-138. DOI: http://dx.doi.org/10.1590/1808-057x201806020.

D’Souza, M., Aragão, I. R., \& De Luca, M. (2018). Análise da Ocorrência de Maquiavelismo e Narcisismo no Discurso nos Relatórios Administrativos de Empresas Envolvidas em Escândalos Financeiros. Revista De Educação E Pesquisa Em Contabilidade (REPeC), 12(3). DOI: https://doi.org/10.17524/repec.v12i3.1899.

D’Souza, M.F., Oliveira, M. L. S., Almeida, J. S. C., Natividade, D. S. (2018). Eu Posso, Você Pode, Eu Posso Mais: Narcisismo e Poder. In: XXI SEMEAD Seminários em Administração, São Paulo.

Dalton, D. W., Buchheit, S., \& McMillan, J. J. (2014). Audit and tax career paths in public accounting: An analysis of student and professional perceptions. Accounting Horizons, 28(2), 213-231. DOI: https://doi.org/10.2308/ acch-50665.

Elbashir, M. Z., Collier, P. A., \& Sutton, S. G. (2011). The role of organizational absorptive capacity in strategic use of business intelligence to support integrated management control systems. The Accounting Review, 86(1), 155-184. DOI: https://doi.org/10.2308/accr.00000010.

Furnham, A., Hyde, G., \& Trickey, G. (2014). The dark side of career preference: dark side traits, motives, and values. Journal of Applied Social Psychology, 44(2), 106-114. DOI: https://doi.org/10.1111/jasp.12205.

Furtner, M. R., Rauthmann, J. F., \& Sachse, P. (2011). The self-loving self-leader: an examination of the relationship between self-leadership and the dark triad. Social Behavior and Personality, 39(3), 369-380. DOI: https://doi. org/10.2224/sbp.2011.39.3.369.

Gattiker U. E., \& Larwood L. (1988). Predictors for managers'career mobility, success, and satisfaction. Human Relations, 41, 569-591. DOI: https://doi.org/10.1177/001872678804100801.

Gonzalez, R. A. (2016). Esforço discricionário no trabalho: um estudo à luz da Teoria da Ação Planejada. Tese de Doutorado, Escola de Administração, Universidade Federal da Bahia, Salvador, BA, Brasil.

Hair Jr, J. F., Gabriel, M. L. D. D. S., \& Patel, V. K. (2014). Modelagem de Equações Estruturais Baseada em Covariância (CB-SEM) com o AMOS: orientações sobre a sua aplicação como uma Ferramenta de Pesquisa de Marketing. REMark, 13(2), 43. DOI: https://doi.org/10.5585/remark.v13i2.2718

Hartmann, F. G. H., \& Maas, V. S. (2010). Why business unit controllers create budget slack: involvement in management, social pressure, and machiavellianism. Behavioral Research in Accounting, 22(2), 27-49. DOI: https://doi.org/10.2308/bria.2010.22.2.27.

Hartmann, F., \& Slapničar, S. (2009). How formal performance evaluation affects trust between superior and subordinate managers. Accounting, Organizations and Society, 34(6), 722-737. DOI: https://doi.org/10.1016/j. aos.2008.11.004. 
Hoffman, B. J., Strang, S. E., Kuhnert, K. W., Campbell, W. K., Kennedy, C. L., \& LoPilato, A. C. (2013). Leader narcissism and ethical context: effects on ethical leadership and leader effectiveness. Journal of Leadership \& Organizational Studies, 20(1), 25-37. DOI: https://doi.org/10.1177/1548051812465891.

Holland, J. L. (1997). Making vocational choices: a theory of vocational personalities and work environments. 3rd ed. Odessa, FL: Psychological Assessment Resources.

Holt, T., Burke-Smalley, L. A., \& Jones, C. (2017). An Empirical Investigation of Student Career Interests in Auditing Using the Big Five Model of Personality. In: T.G. Calderon, Advances in Accounting Education: Teaching and Curriculum Innovations (pp. 1-31). Bingley, Reino Unido, Emerald Publishing Limited.

Hsiao, J., \& Casa Nova, S. P. C. (2016). Abordagem geracional dos fatores que influenciam a escolha de carreira em contabilidade. Revista Contabilidade \& Finanças, 27(72). DOI: https://doi.org/10.1590/1808$057 \times 201602980$

Jackson, D. N. (1977). Jackson vocational interest survey manual. Port Huron, MI: Research Psychologists Press.

Jakobwitz, S., \& Egan, V. (2006). The dark triad and normal personality traits. Personality and Individual Differences, 40(2), 331-339. DOI: https://doi.org/10.1016/j.paid.2005.07.006.

Jaskolka, G., Beyer, J. M., \& Trice, H. M. (1985). Measuring and predicting managerial success. Journal of vocational behavior, 26(2), 189-205. DOI: https://doi.org/10.1016/0001-8791(85)90018-1.

Jonason, P. K., Wee, S., \& Li, N. P. (2015). Competition, autonomy, and prestige: Mechanisms through which the Dark Triad predict job satisfaction. Personality and Individual Differences, 72, 112-116. DOI: https:/doi. org/10.1016/j.paid.2014.08.026.

Jonason, P. K., Wee, S., Li, N. P., \& Jackson, C. (2014). Occupational niches and the Dark Triad traits. Personality and Individual Differences, 69, 119-123. DOI: https://doi.org/10.1016/j.paid.2014.05.024.

Jones, D. N. \& Paulhus D. L. (2009). Machiavellianism. In M. R., Levy, \& R. H., Hoyle. (Eds.). Individual differences in social behavior (pp. 93-108). New York: Guilford.

Jones, D. N., \& Figueredo, A. J. (2013). The core of darkness: uncovering the heart of the dark triad. European Journal of Personality, 27(6), 521-531. DOI: https://doi.org/10.1002/per.1893.

Jones, D. N., \& Paulhus, D. L. (2010). Different provocations trigger aggression in narcissists and psychopaths. Social Psychological and Personality Science, 1(1),12-18. DOI: https://doi.org/10.1177/1948550609347591.

Jones, D. N., \& Paulhus, D. L. (2011). Differentiating the dark triad within the interpersonal circumplex. In L. M., Horowitz, \& S., Strack. Handbook of interpersonal psychology (pp. 249-269). New York: Wiley and Sons.

Jones, D. N., \& Paulhus, D. L. (2014). Introducing the short Dark Triad (SD3): a brief measure of dark personality traits. Assessment, 21(1), 28-41. DOI: https://doi.org/10.1177/1073191113514105.

Judge T.A., \& Bretz R. D. (1994). Political influence behavior and career success. Journal Management, $20,4345$.

Judge T.A., Cable D. M., Boudreau J. W. \& Bretz RD. (1995). An empirical investigation of the predictors of executive career success. Personnel Psychology, 48, 485-519. DOI: https://doi.org/10.1111/j.1744-6570.1995. tb01767.x.

Judge, T. A., Piccolo, R. F., \& Kosalka, T. (2009). The bright and dark side of leader traits: a review and theoretical extension of the leader trait paradigm. The Leadership Quarterly, 20(6), 855-875. DOI: https:// doi.org/10.1016/j.leaqua.2009.09.004.

Korman, A. K., Wittig-Berman, U., \& Lang, D. (1981). Career success and personal failure: Alienation in professionals and managers. Academy of management journal, 24(2), 342-360. DOI: https://doi. org/10.2307/255846.

Kowalski, C. M., Vernon, P. A., \& Schermer, J. A. (2017). Vocational interests and dark personality: Are there dark career choices? Personality and individual differences, 104, 43-47. DOI: https://doi.org/10.1016/j. paid.2016.07.029.

Langaro, F. N. \&Benetti, S. P. C. (2014). Subjetividade contemporânea: narcisismo e estados afetivos em um grupo de adultos jovens. Revista de Psicologia Clínica, 26, 2, p.197-215. 
Lau, C. M., \& Roopnarain, K. (2014). The effects of nonfinancial and financial measures on employee motivation to participate in target setting. The British Accounting Review, 46(3), 228-247. DOI: https://doi.org/10.1016/j. bar.2014.02.006.

Lau, V. P., \& Shaffer, M. A. (1999). Career success: the effects of personality. Career development international, 4(4), 225-231. DOI: https://doi.org/10.1108/13620439910270607.

Law, P. K. (2010). A theory of reasoned action model of accounting students' career choice in public accounting practices in the post-Enron. Journal of Applied Accounting Research, 11(1), 58-73. DOI: https://doi. org/10.1108/09675421011050036.

Lee, L., Petter, S., Fayard, D., \& Robinson, S. (2011). On the use of partial least squares path modeling in accounting research. International Journal of Accounting Information Systems, 12(4), 305-328. DOI: https:// doi.org/10.1016/j.accinf.2011.05.002.

Lima, G., Avelino, B., \& Cunha, J. (2018). Narcisismo: estudantes de contabilidade estão usando seu narcisismo para melhorar o desempenho? Revista de Contabilidade e Organizações, 11(31), 58-74. https://doi. org/10.11606/rco.v11i31.137775.

Lima, R. N., Filho, Souza, A., \& D’Souza, M. F. (2016). Narcissistic personality traits in the context of accounting education: an application of the item response theory. Anais do Encontro da Associação Nacional de Pósgraduação e Pesquisa em Administração, Salvador, BA, Brasil, 40.

Maccoby, M. (2004, January). Narcissistic leaders: the incredible pros, the inevitable cons. The Harvard Business Review, 78(1), 68-78.

Mchoskey, J. W. (1999). Machiavellianism, intrinsic versus extrinsic goals, and social interest: a self-determination theory analysis. Motivation and Emotion, 23(4), 267-283. DOI: https://oi.org/10.1023/A:1021338809469.

Nicolaou, A. I., Sedatole, K. L., \& Lankton, N. K. (2011). Integrated Information Systems and Alliance Partner Trust. Contemporary Accounting Research, 28(3), 1018-1045. DOI: https://doi.org/10.1111/j.19113846.2011.01077.x.

Omar, M. K., Zakaria, A., Ismail, S., Sin, J. S. L., \& Selvakumar, V. (2015). Job selection preferences of accounting students in Malaysian private universities. Procedia Economics and Finance, 31, 91-100. DOI: https://doi. org/10.1016/S2212-5671(15)01135-1.

Paulhus, D. L., \& Williams, K. (2002). The Dark Triad of personality: narcissism, machiavellianism, and psychopathy. Journal of Research in Personality, 36(6), 556-563. DOI: https://doi.org/10.1016/S00926566(02)00505-6.

Qin, F., \& Xu, F. (2013). Machiavellians' job performance and career success in workplaces: a meta-analysis. Advances in Psychological Science, 21(9), 1542-1553. DOI: https://doi.org/10.3724/SP.J.1042.2013.01542.

Raskin, R., \& Terry, H. (1988). A principal-components analysis of the narcissistic personality inventory and further evidence of its construct validity. Journal of Personality and Social Psychology, 54(5), 890-902. DOI: http://dx.doi.org/10.1037/0022-3514.54.5.890.

Rosenthal, S. A., \& Pittinsky, T. L. (2006). Narcissistic leadership. The Leadership Quarterly, 17, 617-633. DOI: https://doi.org/10.1016/j.leaqua.2006.10.005.

Schermer, J. A., \& MacDougall, R. (2011). The Jackson Career Explorer in relation to the Career Directions Inventory. Journal of Career Assessment, 19, 442-451. DOI: https://doi.org/10.1177/1069072711409721.

Schneider, T. J., McLarnon, M. J., \& Carswell, J. J. (2017). Career interests, personality, and the Dark Triad. Journal of Career Assessment, 25(2), 338-351. DOI: https://doi.org/10.1177/1069072715616128.

Smith, S. F., \& Lilienfeld, S. O. (2013). Psychopathy in the workplace: the knowns and unknowns. Aggression and Violent Behavior, 18, 204-218. DOI: https://doi.org/10.1016/j.avb.2012.11.007.

Spurk, D., Keller, A. C., \& Hirschi, A. (2016). Do bad guys get ahead or fall behind? Relationships of the dark triad of personality with objective and subjective career success. Social Psychological and Personality Science, 7(2), 113-121. DOI: https://doi.org/10.1177/1948550615609735.

Sutin, A. R., Costa, P. T., Miech, R., \& Eaton, W. W. (2009). Personality and career success: Concurrent and longitudinal relations. European journal of personality, 23(2), 71-84. DOI: https://doi.org/10.1002/per.704. 
VandenBos, G. R. (Org.). (2010). Dicionário de Psicologia da American Psychological Association (D. Bueno et al., Trad.) Porto Alegre: Artmed.

Volmer, J., Koch, I. K., \& Göritz, A. S. (2016). The bright and dark sides of leaders' dark triad traits: Effects on subordinates' career success and well-being. Personality and Individual Differences, 101, 413-418. DOI: https://doi.org/10.1016/j.paid.2016.06.046.

Wakefield, R. L. (2008). Accounting and machiavellianism. Behavioral Research in Accounting, 20(1), 115-129. DOI: https://doi.org/10.2308/bria.2008.20.1.115.

Weston, R. (2006). A brief guide to structural equation modeling. The Counseling Psychologist, 34(5), 719-51. DOI: https://doi.org/10.1177/0011000006286345.

Wexler, M. N. (2008). Conjectures on systemic psychopathy: reframing the contemporary corporation. Society and Business Review, 3 (3). DOI: https://doi.org/10.1108/17465680810907305.

\section{Como citar este artigo}

D'Souza, M. F., \& Lima, G. A. S. F. de. (2018). Escolha de carreira: o dark triad revela revela interesses de estudantes de Contabilidade. Revista de Contabilidade e Organizações, 12:e151837. DOI: http://dx.doi. org/10.11606/issn.1982-6486.rco.2018.151837 


\section{APÊNDICE A - Short Dark Triad (SD3)}

As assertivas a seguir podem estar relacionadas com suas atitudes ou comportamento. Não há respostas certas ou erradas. Ao respondê-las, atribua valores de 1 a 5, de acordo com a seguinte escala: 1 - Discordo totalmente, 2 - Discordo, 3 - Não concordo nem discordo, 4 - Concordo, 5 - Concordo totalmente.

\section{Assertivas}

\begin{tabular}{l}
\hline Maquiavelismo \\
\hline M1: Não é prudente contar seus segredos \\
M2: Em geral, as pessoas não trabalham com afinco, a menos que tenham que fazê-lo \\
M3: Você precisa ter pessoas importantes ao seu lado, não importa a que custo \\
M4: Evite o conflito direto com os outros, porque eles poderão ser úteis no futuro \\
M5: É prudente manter-se a par de informações que você poderá usar contra as pessoas mais tarde \\
M6: Você deve esperar pelo momento certo para dar o troco às pessoas \\
M7: Existem coisas que você deve esconder das outras pessoas porque elas não precisam saber \\
M8: Certifique-se de que seus planos beneficiam você, não os outros \\
M9: A maioria das pessoas pode ser manipulada
\end{tabular}

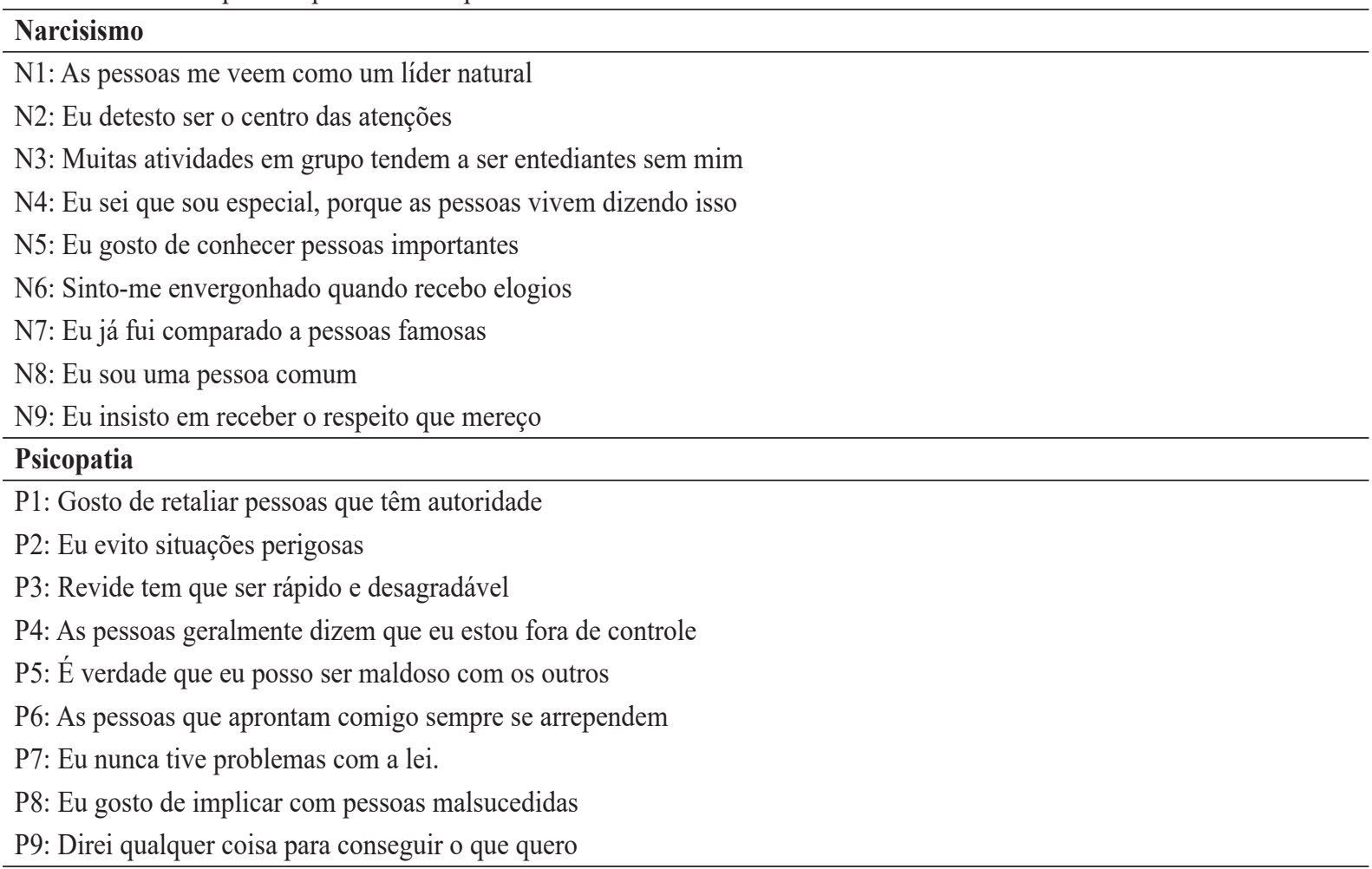

Nota: Em consonância com o instrumento de pesquisa, as respostas às assertivas (N2, N6, N8, P2 e P7) foram revertidas: resposta 1 para 5 ; resposta 2 para 4 e a resposta 3, manteve-se sem reversão. 
APÊNDICE B - Frequência das variáveis sociodemográficas

\begin{tabular}{|c|c|c|c|}
\hline Variáveis & & Frequência & $\%$ \\
\hline \multirow{3}{*}{ Gênero do estudante } & Feminino & 825 & 58,8 \\
\hline & Masculino & 579 & 41,2 \\
\hline & Total & 1.404 & 100,0 \\
\hline \multirow{6}{*}{ Faixa etária do estudante } & De 17 a 25 anos & 863 & 61,5 \\
\hline & De 26 a 35 anos & 425 & 30,3 \\
\hline & De 36 a 45 anos & 77 & 5,5 \\
\hline & Acima de 45 anos & 28 & 2,0 \\
\hline & Não informou & 11 & 0,8 \\
\hline & Total & 1.404 & 100,0 \\
\hline \multirow{3}{*}{ Exerce atividade remunerada? } & Sim & 204 & 15,5 \\
\hline & Não & 1200 & 85,5 \\
\hline & Total & 1.404 & 100,0 \\
\hline \multirow{10}{*}{ Escolaridade dos Pais } & Analfabeto & 17 & 1,2 \\
\hline & Ensino fundamental Incompleto & 173 & 12,3 \\
\hline & Ensino fundamental Incompleto & 145 & 10,3 \\
\hline & Ensino Médio Incompleto & 98 & 7,0 \\
\hline & Ensino Médio Completo & 470 & 33,5 \\
\hline & Ensino Superior Incompleto & 100 & 7,1 \\
\hline & Ensino superior Completo & 229 & 16,3 \\
\hline & Especialização, Mestrado, Doutorado & 147 & 10,5 \\
\hline & Não Sei & 25 & 1,8 \\
\hline & Total & 1.404 & 100,0 \\
\hline \multirow{6}{*}{ Renda familiar } & Um salário mínimo & 165 & 11.8 \\
\hline & De 2 a 5 salários mínimos & 735 & 52,6 \\
\hline & De 6 a 10 salários mínimos & 358 & 25,5 \\
\hline & De 10 a 20 salários mínimos & 108 & 7,7 \\
\hline & Acima de 20 salários & 34 & 2,4 \\
\hline & Total & 1.404 & 100,0 \\
\hline \multirow{6}{*}{ Região do curso } & Nordeste & 799 & 56,9 \\
\hline & Norte & 17 & 1,2 \\
\hline & Sudeste & 466 & 33,2 \\
\hline & Centro Oeste & 2 & 0,1 \\
\hline & Sul & 120 & 8,5 \\
\hline & Total & 1.404 & 100,0 \\
\hline
\end{tabular}


APÊNDICE C - Parametrização das variáveis

Variável Parametrização

Gênero do estudante Variável categórica: 1 para o gênero masculino e 0 para o gênero feminino.

Faixa etária do estudante Variável categórica: 1 para a faixa entre 17 a 25 anos; 2 para a faixa entre 26 a 35 anos; 3 para a faixa entre 36 a 45 anos e 4 para a faixa acima de 46 anos.

Semestre no curso Variável que correspondente ao semestre em que o estudante está matriculado. No Brasil, o curso de contabilidade dura entre 8 e 10 semestres.

Exerce atividade remunerada? Variável categórica: 1 para Sim e 0 para Não.

Renda familiar Variável categórica: 1 para 1 salário mínimo; 2 para 2 salários mínimos; 3 para 3 salários mínimos, 4 para 4 salários mínimos e 5 para 5 salários mínimos.

Escolaridade dos pais Variável categórica: 1 para Analfabeto, 2 para Ensino Fundamental Incompleto, 3 para Ensino Fundamental (Completo), 4 para Ensino Médio (Incompleto), 5 para Ensino Médio (Completo), 6 para Ensino Superior (Incompleto), 7 para Ensino Superior (Completo), 8 para Especialização, 9 para Mestrado ou Doutorado e 9 para Não sei

Região do curso Variável categórica: 1 para Nordeste; 2 para Norte; 3 para Sudeste, 4 Centro Oeste e 5 para Sul. 